\title{
A EDUCAÇÃO COMO FORMA DE RESSOCIALIZAÇÃO
}

\author{
Keilor Dasilva de Sousa ${ }^{1}$ \\ Thiago Vieira da Cunha Pereira ${ }^{2}$ \\ Rafaela Espinosa Peres ${ }^{3}$
}

RESUMO: O presente artigo trata-se de um estudo sobre A educação como forma de ressocialização do detento. Por meio de uma revisão de literatura com pesquisa bibliográfica em que se busca informações em livros, revistas, publicações e demais materiais sobre o assunto. Entre os objetivos está à busca de maiores informações sobre o tema. A educação é um direito garantido através de Leis à todos os cidadãos e para aqueles que encontram-se privados de sua liberdade não é diferente, no entanto a superlotação e a precariedade causam inúmeros obstáculos para que tenham acesso à educação que é um fator chave para sua ressocialização.

Palavras-chave: Educação. Ressocialização. Leis.

\section{INTRODUÇÃO}

A principal finalidade da pena é disciplinar aquele cidadão que em um determinado momento afrontou as normas legais de convivência impostas pela sociedade. Após seu julgamento o mesmo é afastado do meio social, sendo privado de sua liberdade.

O objetivo principal da pena é fazer com que o recluso reflita sobre seu erro e busque repará-lo, modificando sua maneira de pensar, no entanto o que pode-se observar é que a pena assume caráter, essencialmente retribuitivo, não conseguindo apresentar a função reformadora/restauradora, ao contrário, seve-se ao pape de corromper o infrator, o qual antes possuía antecedentes primários e especializar aquele á imiscuído na criminalidade.

A reeducação significa o ato de educar novamente aquele que se afastou das normas, socialmente impostas. $\mathrm{O}$ ato de reeducar nesse sentido seria alcançado com o cumprimento da pena, a qual teria uma função pedagógica e correcional.

\footnotetext{
I Policial Penal, formado em Direito pela UCPEL.

2 Policial Penal, licenciado em Geografia pela UFPEL

3 Policial Penal, formada em Direito pela FURG.
} 


\section{DESENVOLVIMENTO}

O sistema penitenciário brasileiro é conhecido pelo descaso dos poderes competentes, da falta de efetivação do estipulado na Lei de Execução Penal, a qual possui como um dos principais objetivos a promoção da ressocialização dos apenados e posteriormente a reinserção dos mesmos ao convívio social.

O encarceramento continua exatamente o mesmo das épocas remotas: o afastamento de indivíduos que delinquem - aglomerando, em sua maioria, os menos privilegiados. Parafraseando, a desigualdade social anda de mãos dadas com o ato criminal, visto que, para que boa parte da população permaneça no estado de miséria, pobreza absoluta e privado da educação básica de um Estado, uma outra parcela tem de estar se beneficiando. (STUDART, 2017, p. 7).

Uma das maneiras de proporcionar um retorno de maneira positiva do reeducando ao convívio social é através do trabalho, aproveitando do período em que o mesmo cumpriu apena para proporcionar a qualificação profissional do preso, para que ao sair do sistema prisional, este possa encontrar um meio de prover seu sustento e o da sua família através de um trabalho digno.

O Brasil é o terceiro país com a maior população carcerária do mundo, onde a superlotação ocorre devido ao mesmo motivo, o número de indivíduos registrados no sistema prisional é muito maior do que a capacidade das celas.

Existe o pensamento de que somente a prisão é capaz de transformar os indivíduos que ali estão, há uma falsa ilusão de que esses indivíduos teriam a oportunidade de refazer sua existência para depois serem devolvidos à sociedade, no entanto o que se pode perceber é o fracasso de tal propósito, pois os índices de reincidência e criminalidade mostram-se cada vez maiores, e os presos em sua maioria não se transformam.

Ressocializar não é tarefa das mais fáceis. Ressocializar apenados é ainda mais difícil porque vai de encontro aos dogmas sociais segundo os quais a recuperação 'destes indivíduos' não faz parte do mundo real, não é passível de ser realizada, não merece que se desprendam esforços neste sentido, devendo os apenados permanecer no submundo porque passaram à condição de sub-humanos. $O$ encarceramento continua exatamente o mesmo das épocas remotas: o afastamento de indivíduos que delinquem - aglomerando, em sua maioria, os menos privilegiados. Parafraseando, a desigualdade social anda de mãos dadas com o ato criminal, visto que, para que boa parte da população permaneça no estado de miséria, pobreza absoluta e privado da educação básica de um Estado, uma outra parcela tem de estar se beneficiando. ( STUDART, 2017, p. 7).

É dever do Estado promover possibilidades a fim de que o reeducando quando estiver em liberdade, não volte a cometer crimes, o encarceramento acaba provocando 
inúmeras perdas como: trabalho, distanciamento familiar, saúde, dignidade, moradia, entre outros. A assistência governamental é de suma importância para que o egresso do sistema prisional possa refazer sua vida contribuindo positivamente com a sociedade.

Reforçando isso com o entendimento de que a ressocialização dos apenados é o principal objetivo da sansão penal, a Lei de Execução Penal (LEP) n ${ }^{\circ}$ 7.210/1984, (BRASIL, 1984) dispões em seu Art.I que "a execução penal tem por objetivo efetivar as disposições de sentença ou decisão criminal e proporcionar condições para a harmônica integração social do condenado e do internado".

O ex detento será perseguido pelo estigma, o qual o marca pela sua passagem no sistema carcerário, fardo esse que ele carregará durante anos, o impedindo muitas vezes de ser reinserido novamente na sociedade como um cidadão comum, bem como ser incluído novamente no mundo do trabalho.

\footnotetext{
Todos os ex detentos, ao sair da prisão se deparam com a difícil tarefa de se inserir no contexto fora da prisão, momento em que mais enfrentarão a manifestação de preconceitos, que lhes impõe barreiras quase que intransponíveis. O estigma de expresidiário acompanha o indivíduo que cumpre pena privativa de liberdade para sempre. Com o término legal da pena, está terminado o processo, mas a pena, o sofrimento e o castigo, não, porque a sociedade fixa cada um no passado. Roubou, poderá roubar ainda. A pena, se não mesmo sempre, nove vezes em dez não termina nunca. (CARNELUTTI, 1995, p. 77).
}

Por receio a sociedade acaba não oferencendo oportunidade para ex presidiários o que acaba por contribuir para que continuem sem trabalhar, estudar e até retornar à prática de delitos, pois não encontram uma forma de seguir uma vida honesta focada em um trabalho ou estudo.

Muitos fatores auxiliam a reinserção do preso na vida em sociedade, entre eles se configuram através da oferta de emprego, estudo de qualidade, cursos profissionalizantes e de qualificação, auxílio com material, ajuda religiosa, psicológica, social, à saúde e jurídica, e além de tudo é de suma importância que seja proporcionada a esses indivíduos uma reflexão sobre as condutas ilegais que cometeram, de forma que as incentive a agirem em acordo com a ética, os bons costumes, os valores moralmente constituídos pela sociedade e primordialmente com a legislação.

A assistência social defendida através da Lei de Execução Penal tem como objetivo reintegrar interno ou presidiário ao convívio em sociedade através de um sistema progressivo de pena. 
O sistema penitenciário brasileiro utiliza um sistema progressivo de pena, ou seja, conforme o andamento da pena do interno ele vai progredindo de um sistema mais gravoso para um mais brando após o cumprimento de um tempo de pena coforme a prática do delito que cometeu. O mesmo sistema não admite a progressão direta, ou seja, mesmo que o preso preencha os critérios objetivos(tempo) e subjetivos(condição social e bom comportamento) o mesmo só alcança o regime mais brando , após cumprir seu percentual de pena. Em outra palavras para o mesmo avançar para o regime aberto por exemplo terá que cumprir o percentual de pena do regime fechado, semi-aberto e após chegar ao aberto.

Devolver ao detento a dignidade, elevar a sua autoestima, por meio da efetivação de projetos que tragam proveito profissional. O trabalho, sem dúvidas, é um dos fatores que resgatam a dignidade humana do apenado. A falta de políticas públicas e o descaso fazem com que o processo de reintegração do apenado fique cada vez mais distante das penitenciárias brasileiras. (STUDART, 2017, p. 7).

O trabalho no sistema carcerário é considerado como um benefício, pois o mesmo representa a via de retorno ao convívio social, para os presos o trabalho significa uma aproximação da possibilidade de ser novamente inserido na sociedade e por consequência distanciar-se do mundo da criminalidade.

O trabalho é importante na conquista de valores morais e materiais; a instalação de cursos profissionalizantes possibilita a resolução de dois problemas, um cultural e outro profissional. Muda o cenário de que a grande maioria dos presos não possui formação e acabam por enveredar, por falta de opção, na criminalidade, e facilitam a sua inserção no mercado de trabalho, uma vez cumprida a pena. (ZACARIAS, 2006, p. 6r).

Para que de fato ocorra a ressocialização é preciso que o Estado saiba os rumos a tomar, que se faça uma análise individualizada sobre a pena de cada detento, levando sempre em consideração que no sistema prisional existem pessoas diversas, desiguais, devendo ser tratadas na medida da sua igualdade, cabe ressaltar que a maioria dos encarcerados vem de classes sociais desfavorecidas economicamente.

O trabalho é o precursor da nossa humanidade, pois ele possibilita uma ação transformadora sobre o indivíduo, pois através do trabalho que é construída a identidade do sujeito.

A reinserção e ressocialização do egresso em sociedade, não é fácil de ser alcançado, mesmo tendo apenados que desejam e planejam evoluir na vida, sonhando com um futuro melhor, na sua maioria os egressos enfrentam preconceitos da sociedade, a qual não 
oportuniza caminhos para a sua inclusão social, onde um dos fatores se dá pelo fato do egresso não possuir qualificação profissional.

\begin{abstract}
Egressos do cárcere estão sujeitos a uma outra terrível condenação: o desemprego. Pior que tudo, são atirados a uma obrigatória marginalização. Legalmente, dentro dos padrões convencionais não podem viver ou sobreviver. A sociedade que os enclausurou, sob o pretexto hipócrita de reinseri-los depois em seu seio, repudiaos, repele-os, rejeita-os. Deixa, aí sim, de haver alternativa, só o ex condenado tem uma solução: incorporar-se ao crime organizado. Não é demais martelar: a cadeia fabrica delinquentes, cuja quantidade cresce na medida e na proporção em que for maior o número de condenado. (SILVA, 1991, p.40).
\end{abstract}

A sociedade precisa entender que as oportunidades dadas aos egressos refletem de maneira indireta na segurança pública como um todo, tendo em vista que ela é de responsabilidades de todos e obrigação do Estado.

Diante de todos os dilemas que envolvem o sistema penitenciário no Brasil, o Estado possui como intuito reduzir esses problemas, e para isso desenvolveu duas formas o primeiro foi o estudo, onde o apenado tem a oportunidade de concluir ensino médio ou até mesmo optar em fazer algum curso de nível técnico ou superior, o segundo é o trabalho, que dentre tantos benefícios, um é imprescritível que é a dignidade da pessoa humana.

Considerando que as políticas públicas devem ser voltadas ao atendimento de demandas da população, e neste caso, em específico e inclusive, de pessoas que estão sob custódia do Estado, recorde-se que a Lei n ${ }^{\circ}$ 7.201/1984 (Lei de Execução Penal) representa o marco legislativo voltada ao desenvolvimento de ações pelo Estado com o intuito de inserir egressos no mercado de trabalho. Em seu Art. Ioo determina que é dever do Estado a assistência ao preso e ao internado tendo como objetivo a prevenção do crime e a orientação do mesmo a retornar à convivência em sociedade (BRASIL, 1984).

Dentre os fatores que contribuem para a dificuldade de se reinserir e ressocializar o egresso novamente a sociedade, seria a superlotação, má distribuição estatal, assim como a falta de investimentos na capacitação desses indivíduos dentro e fora dos presídios.

O trabalho na vida de qualquer indivíduo, possui enorme importância, sendo ele fundamental para o desenvolvimento e libertação econômica de todo o ser humano, a Constituição Federal estabelece que todos os indivíduos devem ter direito a assistência social, para que possa ser auxiliado de maneira a facilitar seu retorno ao convívio social, no entanto esses preceitos nem sempre são colocados em prática na maneira como foram e para qual foram criados, o que acaba dificultando a reinserção do egresso em sociedade.

No que diz respeito ao cumprimento das normas de tratamento humanitário, a realidade dos presídios brasileiros se caracteriza pela ineficiência na gestão da execução 
penal pelo Estado, pois os presídios são considerados como escolas do crime, por se tratar de espaços propícios a ilegalidade, visto que o Governo não cumpre o princípio básico da pena que é a preparação do egresso para uma reabilitação social.

O cumprimento da pena na prisão não deve resumir-se exclusivamente no trancafiamento de uma pessoa em estabelecimento prisional para o efeito de ser submetida a normas de segurança e de disciplina. Ao afastamento obrigatório do recluso da vida em liberdade devem corresponder compensações que visem estimulá-lo ao exercício de direitos não atingidos pela condenação, atenuando, assim, os efeitos desse afastamento e possibilitando promoção de um processo de gradual reintegração social. (...) os efeitos deletérios da internação forçada devem ser evitados através de um procedimento prisional que reduza significativamente o perigo da dessocialização. (FRANCO, 2005, p. 65).

Diariamente são noticiados pela mídia o caos do sistema penitenciário brasileiro, como a carência de políticas públicas penais, superlotação, falta de infraestrutura, e rebeliões.

Essas questões que assolam os presídios brasileiros pedem uma reflexão sobre seus aspectos, papel esse que é de suma importância que seja assumido pela sociedade pois não trata-se apenas de um problema de segurança pública mas sim de um problema social, tendo em vista que o sistema prisional é negligenciado pelo poder público e diversas vezes também pela sociedade, a qual age com desprezo em relação a população carcerária.

A ausência prolongada do condenado de seu meio social acarreta um desajustamento que somente poderá ser superado se forem oferecidas a ele condições adequadas à sua reinserção social quando for liberado. É preciso, pois, que toda a comunidade seja conscientizada da missão que lhe cabe na tarefa de assistir aquele que, tendo transgredido a lei penal, está resgatando o débito criado com a prática do crime. (MIRABETE,1988, p.234).

No que diz respeito a qualificação profissional é notório que através dela os apenados poderiam alcançar uma requalificação no mercado de trabalho, tendo em vista que quando tornam-se egressos existem diversos obstáculos para conseguir um emprego novo, visto que sem uma qualificação é praticamente impossível este retorno ao trabalho tornando-se mais fácil o retorno a criminalidade.

Boa parte dos apenados, entram no mundo da criminalidade mesmo antes de serem inserido no sistema prisional, e muitos não possuem definido uma profissão qualificada, tendo isso em vista dentro do sistema é levado à ele oportunidades, como cursos técnicos ou profissionalizantes, onde proporcionarão a eles uma qualificação profissional a qual poderá ser seguida após sua saída do sistema prisional, conseguindo assim disputar por vagas no mercado de trabalho. 
O trabalho penal deve ser concebido como sendo por si mesmo uma maquinaria que transforma o prisioneiro violento, agitado, irrefletido em uma peça que desempenha seu papel com perfeita regularidade. A prisão não é uma oficina; ela é, ela tem que ser em si mesma uma máquina de que os detentos-operários são ao mesmo tempo as engrenagens e os produtos; [...] Se no fim das contas, o trabalho da prisão tem um efeito econômico, é produzindo indivíduos mecanizados segundo as normas gerais de uma sociedade industrial. ( FOUCAULT, 1999, p. 27I).

O trabalho é um pilar fundamental para a concretização da ressocialização, além de dignificar o homem, tornou-se algo essencial para a subsistência da pessoa.

A LEP ressalta que o trabalho penitenciário deve ser organizado contendo obrigações e direitos, bem como os direitos trabalhistas, com a capacitação profissional e o trabalho realizado nos presídios poderá haver condições para uma harmônica integração do apenado na sociedade, tendo em vista que dentro do estabelecimento prisional é difícil realizar a realizar a ressocialização sem que haja a oferta de trabalho.

O apenado que trabalha possui o benefício da redução da pena, assim como a frequência em aulas ministradas, o detento a cada três dias trabalhados, subtrai um dia de sua pena, tendo a chance para corrigir o seu erro, dessa maneira ele tende a colaborar com o trabalho da ressocialização.

Nota-se que o trabalho é essencial e é preciso que seja ofertado ao detento dentro do sistema prisional, o trabalho do condenado, como dever social bem como condições dignas resultará na finalidade educativa e produtiva.

\section{CONCLUSÃO}

Existe a possibilidade de se educar no sistema prisional, no entanto há um grau de complexidade, uma série de fatores que impossibilita que a prática de educação aconteça realmente, pois não são todos os presos que tem acesso à educação porque nem todos os presídios possuem uma sala de aula.

Fornecer e investir em uma educação de qualidade é uma forma de ressocializar as pessoas privadas de liberdade, possibilitando-as ao final do cumprimento da pena que tenham opções que vão além do cometimento de novos crimes, pois uma boa formação profissional e educacional proporcionam melhores alternativas e uma nova perspectiva de vida. 
É preciso no entanto que hajam efetivas formulações para a Educação por parte do Estado e uma conscientização por parte da sociedade para que esses egresso do sistema penitenciário possuam uma real chance quando estiverem em liberdade.

\section{REFERÊNCIAS BIBLIOGRÁFICAS}

BRASIL. Lei de Execução Penal. Lei no․ 7.210, de in de julho de 1984. Brasília, DF. Disponível em: 〈http://www.planalto.gov.br/ccivil_03/leis/17210.htm〉. Acesso em: 20 Nov. 202I.

CARNElUtTi, F. As Misérias do Processo Penal, São Paulo: CONAN, 1995.

FOUCAULT, Michel. Vigiar e punir: nascimento da prisão; tradução de Raquel Ramalhete. Petrópolis, Vozes, 20 ed., 1999. Disponível em: 〈https://www.ufsj.edu.br/portal2repositorio/File/centrocultural/foucault_vigiar_punir.pd f>. Acesso em: i6 de Nov. 202I.

FRANCO, A. S. Crimes Hediondos. $5^{\text {a }}$ ed. São Paulo: Revista dos Tribunais, 2005.

MIRABETE, J. F. Execução Penal. Comentários à Lei 7.210, de II-7-1984. II. ed. São Paulo: Atlas, 2004.

SILVA, Evandro Lins e. De Beccaria a Filippo Gramatica. Sistema penal para o terceiro milênio. Rio de Janeiro: Renavan, I99I.

STUDART, Lucia Maria Curvello. A REINSERÇÃO SOCIAL DOS EGRESSOS DO SISTEMA PRISIONAL BRASILEIRO: Realidade ou Utopia? Episteme Transversalis, [S.1.], v. 5, n. I, ago. 2017. ISSN 2236-2649. Disponível em: 〈http://revista.ugb.edu.br/ojs302/index.php/episteme/article/view/8o〉. Acesso em: 26 Nov.2021.

ZACARIAS, A. E. C. de. Execução penal comentada. 2. ed. São Paulo: Tend Ler, 2006. 